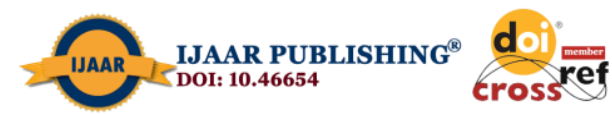

International Journal of Advanced Academic Research (Arts, Humanities and Education) | ISSN: 2488-9849

Vol. 6, Issue 11 (November, 2020) | www.ijaar.org

Journal DOI: 10.46654/ij.24889849

Article DOI: 10.46654/ij.24889849.a61124

\title{
EFFECT OF STEP AEROBICS ON PERCENT BODY FAT AND VISCERAL FAT OF OBESE FEMALE NURSES IN SPECIALIST HOSPITAL BAUCHI
}

\author{
Bulus Yuyu MAIYANGA \\ Physical and Health Education Department, \\ Aminu Saleh College of Education, Azare, \\ Bauchi State, Nigeria. \\ E.A. Gunen \\ Human Kinetics and Health Education Department, \\ Ahmadu Bello University, Zaria, Nigeria. \\ Email: maiyangabulus@yahoo.com
}

\begin{abstract}
This study was conducted to assess the effect of step aerobics on percentage body fat and visceral fat of obese female nurses in specialist hospital Bauchi, Bauchi State. To achieve this purpose, two (2) hypotheses were postulated and tested at 0.05 level of significance. A pre-test and post-test experimental design was employed for the study. The population of the study comprised of sixty two (62) female nurses in Specialist Hospital Bauchi. A sample size of 20 obese female nurses was drawn from the population using purposive sampling technique. The participants were exposed to 12 weeks step aerobics, on 3 alternate days per week, the training programme lasted 30 minutes for the $1^{\text {st }}-4^{\text {th }}$ week, increased to 35 minutes $5^{\text {th }-8 \text { th }}$ and 40 minutes in last four weeks at 45\% - 60\% of HRmax. Omron (BF511) body composition monitor was used to assess the pre and post-test percentage body fat, and visceral fat of the participants. The collected date was analysed using descriptive statistics of means, standard deviation and inferential statistics of student t-test. The result of this study revealed that: step aerobics had significant effect on percent body fat $(p=0.001)$ of obese female nurses in Specialist Hospital of Bauchi. However, step aerobics had no significant effect on visceral fat $(p=0.425)$ of obese female nurses in Specialist Hospital Bauchi. On the bases of the result of this study, it was concluded that step aerobics reducespercentage body fat of obese female nurses in Specialist Hospital Bauchi, Bauchi State but it has no significant effect on visceral fat of the obese nurses. Based on the following conclusions it was recommended that obese female nurses should be enlightened through public lectures by exercise and sport science specialist on the need to perform regular step aerobics to burn down excess body fat. Step aerobics should be encouraged among obese female nurses by exercise and sports science specialist as a mode of exercise for improving physical fitness so as to improve their health.
\end{abstract}

Key words: Obesity, Percent body fat, Visceral Fat, Fitness, Aerobic 


\section{Background to the study}

The human body is generally designed for movement (activity) through which the energy gained through food intake is expended. Thistherefore suggests the importance of physical activity to the body which cannot be over emphasized. Body composition (BC) refers to the relative proportion of body weight in terms of lean body mass and body fat. Lean body mass represents the weight of muscle, bone, internal organs, and connective tissues (Kirchengast, 2010). Body composition can also be viewed as relative amount of body fat and lean bone mass, which includes muscle, bone, water, blood and other non-fat tissues (Venkateswarlu, 2011). In this study, body composition refers to relative amount of body fat, lean body mass which includes bone, muscle, body fluid, internal organs and non-fat tissues. Body composition variables of interest in the study include percentage body fat and visceral fat.

Body fat serves three important functions in the human body, serves as an insulator for conserving body heat; it is the source of metabolic fuel energy; and as padding for protection (Hamid, Rastegar \& Ayoub, 2012). Body fat is essential for physiological homeostasis, and not only as a source of energy but also, to synthesize cell membranes and facilitates intracellular reaction, plays vital role in maintaining healthy skin and hair, insulating body organs against shock, maintaining body temperature, promoting healthy cells functions and serve as energy store for the body (Mengistie, Reddy \&Syam 2013). Hence, a healthy body requires a minimum amount of fat for proper function of the body, but too much storage fat above the required amount can cause the rise of metabolic abnormalities, whereas leanness, such as lowfat mass is important in one's physical performance.

Visceral fat accumulation is due to lack of physical exercise and westernized diet pattern according to change in lifestyle (Kwon, Min, Ahn, Seok, Koo, Kim \& Han, 2010). Visceral fat literally is the fat within the abdomen. Central or abdominal excessive fat has been shown to be an important predicator for increased morbidity and mortality from obesity, diabetes and coronary heart disease (Sandeep, Gokulakrishnan, Velmurugan, Deepa \& Mohan, 2010). Visceral fat is considered by many to behave as an abnormal fat depot, accumulating triglycerides and associated with the metabolic abnormalities that increase cardiovascular disease risk (Ebbert \& Jensen, 2013). This implies that visceral fat is unlike the visible fat just under the skin, visceral fat surrounds the vital organs in the abdomen.

Obesity is an international health problem for adults and the elderly which has led to the development of type 2 diabetes, hence factors for cardiovascular and related disease and is associated with increased cancer risk and renal failure (Chumlea, 2006) The global increase in obesity has raised interest in the complex causes of excessive weight gain, which can be seen as the consequence of a sustained increase in energy intake relative to energy expenditure that is characterized by the accumulation of excess body fat and can be conceptualized as the physical manifestation of chronic energy excess (Uygur, Ucok, Genc, Sener, Uygur \& Songur, 2013). Step aerobics is a form of aerobic activity that is an extension of floor aerobics. This exercise utilizes the same principles and adds an additional cardio element in that extra energy is expended when stepping on and off the riser; it is a versatile training modality that can be made more or less intense by simply changing the height of the step, performing movements through different range of motion or adjusting the step cadence (American Council on Exercise, 2009). 
Step aerobics is a variety added in aerobics which makes it extremely challenging. One tends to lose more calories; adds excitement to the exercise and provides sufficient cardiorespiratory demand to enhance aerobic fitness (Arslan, 2011).

Regrettably, a large number of civil servants including nurseslead sedentary lifestyles due to the nature of their work, which often results in gradual deposition of fatty tissues in the body. This in turn affects their body composition. A daily life pattern of little or less vigorous activity and inactivity has led to fat accumulation and obesity. Consequently, sedentary lifestyle poses a threat to individuals' health because it can lead to an increase or progression in the risk of hypertension, obesity, muscle weakness, postural defects, type 2 diabetes and coronary heart disease.

The researcher observed that female nurses spend most of their time, taking care of patients with a daily life pattern of insufficient time for regular participation in physical activity, modern technology use, time constrain, cultural inhibition, religious belief and attitude have limited physical activity level in a situation that has led to obesity. Nurses are constantly engaged in night-shift duties which deprived them of sleep. Scientific evidence shows that lack of sufficient sleep triggers the release of cortisol, often referred to as "the stress hormone". This hormone promotes the deposit of fat, mainly in the abdominal region. Lack of sleep further increases the release of hormones that stimulate the appetite and make nurses feel hungry even if the body has enough food. Therefore, the imbalance of ghrelin and leptin hormones cause mostnurses to crave for sugary diets, thus increasing body weight. Growth hormone, which regulates the body's fat and muscle's proportion, is released during sleep. Therefore, sleep loss decreases growth hormone levels which in turn slow the body's ability to burn fat and increase lean muscle. It is in the light of this, that this study becomes important so that convenient exercises intervention could be used to inculcate active lifestyle into female nurses.Therefore, this study intends to assess the effect of step aerobics on percent body fat and visceral fat of obese female nurses in specialist hospital Bauchi, Bauchi State.

\section{Research Questions}

This study will attempt to answer the following research questions:

1. Will step aerobics cause modification on percent body fat of obese female nurses in Specialist Hospital, Bauchi, Bauchi State?

2. Will step aerobics modify visceral fats of obese female nurses in Bauchi, Bauchi state?

\section{Purpose of the Study}

The purpose of this study is to assess the effects of step aerobics on:

1. Percent body fat (\%BF) of obese female nurses in Specialist Hospital Bauchi.

2. Visceral fats (VF) of obese female nurses in Specialist Hospital Bauchi. 


\section{Hypotheses}

1. There is no significant effect of 12 weeks step aerobics training on percentbody fat (\% BF) of obese female nurses in Specialist Hospital Bauchi.

2. There is no significant effect of 12 weeks step aerobics training on visceral fat of obese female nurse in Bauchi, Bauchi state.

\section{Methodology}

A pre-test and post-test design was employed for this research. The participants were tested at baseline and were exposed to treatment (step aerobics) for 12 weeks and were tested after the treatment (post-test). The population of the study consisted of sixty-two (62) female nurses in Specialist Hospital Bauchi. Purposive sampling technique was used to select fifteen (15) obese female nurses through assessment of individual participants BMI using body composition monitor. The nurses whose BM1was between 30.0 and $39.99 \mathrm{~kg} / \mathrm{m}^{2}$ (obesity class 1and 11) (WHO, 1999; Guideline and Protocol Advisory Committee, 2011), were used as respondents for the study after agreeing and signing the consent forms. Body Composition Monitor (model BF 511, made by OMRON, Japan) was used to assess percentage body fat and visceral fat of the respondents.

The training lasted for 12 weeks, 3 days per week and between 30 to 40 minute per session and the intensity of the training programme was adjusted based on maximum heart rate $(220-$ age $=$ maximum heart rate $)$ the intensity progressively increased as follows:

$1^{1 \text { st }}$ to 4 th week, training intensity was maintained $45 \%-50 \%$ of HRmax.

$5^{\text {th }}$ to $8^{\text {th }}$ week, training intensity was maintained at $50 \%-55 \%$ of HRmax.

$9^{\text {th }}$ to $12^{\text {th }}$ week, training intensity was maintained at $55 \%-60 \%$ of HRmax.

Table 1. Training Programme

\begin{tabular}{|c|c|c|c|c|c|c|}
\hline Week & Intensity & $\begin{array}{c}\text { Warm } \\
\text { up/ } \\
\text { Stretches }\end{array}$ & $\begin{array}{c}\text { Aerobic } \\
\text { session }\end{array}$ & $\begin{array}{c}\text { Cool } \\
\text { down }\end{array}$ & $\begin{array}{c}\text { Total } \\
\text { time }\end{array}$ & RPE \\
\hline $\begin{array}{c}1^{\text {IST }} \text { to } \\
4^{\text {th }}\end{array}$ & $\begin{array}{c}45 \%-50 \% \\
\text { HRmax }\end{array}$ & 5 min & 20 min & 5 min & 30 min & Light \\
\hline $5^{\text {th }}$ to $8^{\text {th }}$ & $\begin{array}{c}50 \%-55 \% \\
\text { HRmax }\end{array}$ & 5 min & 25 min & 5 min & 35 min & Moderate \\
\hline $\begin{array}{c}9^{\text {th }} \\
\text { to12 }\end{array}$ & $\begin{array}{c}55 \%-60 \% \\
\text { HRmax }\end{array}$ & 5 min & 30 min & 5 min & 40 min & $\begin{array}{c}\text { Somewhat } \\
\text { Hard }\end{array}$ \\
\hline
\end{tabular}


The data collected for this study was analysed using descriptive statistic of means, standard deviations and standard error of estimate to analyse the physical characteristics such as age, height and weight of the participants to give information about the dispersion and the variation of the of data.Student $\mathrm{t}$ - tests (paired $\mathrm{t}$ - test) was used to analyse the post-test effect of step aerobics on the assessed variables of the study. Decision to reject or retain the null hypotheses was made at an alpha level of 0.05 .

\section{Results}

Information on the physical characteristics of the participant before the commencement of the training is presented in table $4: 2: 1$

Table 2: Physical Characteristic of the Participants

\begin{tabular}{llll}
\hline Variable & Mean & SD & SE \\
\hline Age (yrs) & 31.083 & 7.50 & 2.17 \\
Height (m) & 1.617 & 0.066 & 0.02 \\
Weight (pre) $(\mathrm{kg})$ & 90.68 & 6.423 & 1.85
\end{tabular}

Table 2: shows the physical characteristics of the participants, mean age of the participants was $31.083 \pm 7.50$ years with an average height and weight of $1.617 \pm 0.066 \mathrm{~m}$, and $90.68 \pm 6.423 \mathrm{~kg}$ respectively. Data collected at baseline (pre-test) and after $12^{\text {th }}$ weeks (post-test) of step aerobics on percent body fat, skeletal muscle mass, visceral fat and resting metabolic rate(\% BF, SMM, VF and RMR) of obese female nurses in Specialist Hospital Bauchi. The baseline and post-test descriptive statistics of the data is presented in table 3.

Table 3: Mean, Standard Deviation and Standard Error of Pre and Post-test scores of Body Composition variables of the participants

\begin{tabular}{lrrrcccr}
\multicolumn{1}{l}{ Pre-test } & & \multicolumn{5}{c}{ Post-test } \\
Variables & $\mathrm{N}$ & Mean & S.D & S.E & Mean & S.D & S.E \\
\% BF & 12 & 48.43 & 5.52 & 1.60 & 47.15 & 5.18 & 1.50 \\
VF & 12 & 11.25 & 4.60 & 1.33 & 11.63 & 3.54 & 1.02
\end{tabular}

Key: \%BF = Percent Body Fat; VF = Visceral Fat

Table 3: show the pre and post-test mean, standard deviation and standard error of body composition and resting metabolic rate variables of the participants used in this study. An observation of this table revealed that $\% \mathrm{BF}$ decreased from $48.43 \pm 5.52$ to $47.150 \pm 5.18$; VF increased from $11.25 \pm 4.60$ to $11.63 \pm 3.54$. 
To test if these changes were statistically significant, the data was subjected to paired $\mathrm{t}$ test analysis and presented according to hypotheses.

Hypothesis 1: There is no significant effect of step aerobics training on percentage body fat (\% $\mathrm{BF}$ ) of obese female nurses in Specialist Hospital Bauchi

Table 4: $\quad$ Paired t-test Analysis of the Pre and Post Test Effect of Step Aerobics Training on Body Fat (\% BF) of Obese Female Nurses

\begin{tabular}{llccccc}
\hline Variable & Test Period & Mean & SD & DF & T & P \\
\hline PBF & Pre test & 48.4 & 2.54 & & & \\
& & & & 11 & 4.725 & 0.001 \\
& Post test & 47.2 & 2.47 & & & \\
& & & & &
\end{tabular}

$\mathrm{t}(11)=2.201 \quad \mathrm{P} \leq 0.05$

Table 4 shows t-test analysis of pre-test -post-test effect of step aerobics training on \%BF of obese female nurses. An observation of the result revealed that step aerobics had significant effect on \%BF of obese female nurses in Specialist Hospital Bauchi $(\mathrm{P}=0.001)$. Therefore, the null hypothesis which states that there is no significant effect of step aerobics training on percentage body fat $(\% \mathrm{BF})$ of obese female nurses in Specialist Hospital Bauchi is rejected.

Hypothesis 2: There is no significant effect of step aerobics training on visceral fat of obese female nurses in Specialist Hospital Bauchi.

Table 5: $\quad$ Paired t-test Analysis of the Pre and Post Test Effect of Step Aerobics Training on Visceral Fat of Obese Female Nurses

\begin{tabular}{|c|c|c|c|c|c|c|}
\hline Variable & Test Period & Mean & SD & $\mathrm{DF}$ & $\mathrm{T}$ & $\mathrm{P}$ \\
\hline & Pre test & 11.25 & 4.60 & & & \\
\hline \multirow[t]{2}{*}{ VF } & & & & 11 & -0.840 & 0.425 \\
\hline & Post test & 11.63 & 3.53 & & & \\
\hline
\end{tabular}

$$
\mathrm{t}(11)=2.201 \quad \mathrm{P} \leq 0.05
$$

Table 5 shows t-test analysis of pre-test post-test effect of step aerobics on VF of obese female nurses. An observation of this result revealed that step aerobics had no significant effect on visceral fat of obese female nurses in Specialist Hospital Bauchi (P 0.425). Therefore, the null hypothesis which states that there is no significant effect of step aerobics training on visceral fat (VF) of obese female nurses in Specialist Hospital Bauchi is retained. 


\section{Discussion}

This study assessed the effect of step aerobics on percentage body fat and visceral fat of obese female nurses in specialist hospital Bauchi, Bauchi State. With regards to percentage body fat, the result of this study revealed that 12 weeks step aerobics training had significant effect on percentage body fat of obese female nurses in Specialist Hospital Bauchi $(p=0.001)$. The result of this study agreed with that of Lehri and Mokha (2006) found significant reduction in percent body fat of females after 6 weeks of aerobic training. This study support study of Vatansev and Cakmakci (2010) who found significant effect of 8 weeks step aerobics on percentage body fat of the experimental group. This finding is in consonancewith the findings of Arslan (2011) who found that regular aerobics exercise improve cardiorespiratory endurance (ability of the heart, lungs, blood vessels and associated tissues) to use oxygen to produce energy needed for activity and thus burn off excess body fat. The result of this study also support the findings of Najafnia, Bararpour, Amirinejahad and Nakhaee (2013) which confirmed that step aerobic exercises lead to a significant decrease in fat percentage $(\mathrm{p}=0 / 02)$ among active and inactive women in Kermanshah Province Iran. The result of this study also support the result of CakmakciArslan, Taskin, and Cakmackci (2011) who found a significant decrease of percentage body fat of obese women after 12 weeks of aerobic dance $(p<0.05)$. The finding also corroborate the study of Willis, Slentz, Bateman, Shields, Piner, Bales, Houmard and Kraus (2012) who found that low to moderate intensities aerobic training significantly reduce measures of percent body fat. The result further agreed with the findings of Merrick, Bacher, Carmeli and Kodesh (2013) and Duman (2013) who observed significant $(\mathrm{p}=0.001)$ effect on percentage body fat of obese women.

With regards to visceral fat, the result of this study revealed that 12 weeks step aerobics had no significant effect on visceral fat of obese female nurses in Specialist Hospital Bauchi $(\mathrm{p}=$ 0.0425). The most important cause of accumulation of visceral fat is lack of exercise; aerobics is known as an exercise mode that burn down excess fat and decrease visceral fat more effectively than other exercise methods, facilitate lipid mobilization and oxidation in the body. Engaging in step aerobics will be of benefit to obese female nurses whom may be of sedentary life style. Kwon, et al (2010) observed that moderate level exercise at $60 \%$ maximal oxygen consumption rate for 60 minutes, 5 times per week resulted in a significant decrease in abdominal visceral fat mass after 12 weeks of aerobics. This result may be influenced by lack of resistance programme which can cause changes in visceral fat. The findings of this study is in contrast with the findings of a study conducted by Mengistie (2013) who reported significant $(p=0.001)$ changes in visceral fat from baseline records after 12 weeks of aerobic and resistance exercise.This conflict may be explained by the low intensity of the exercise compared with the resistance training which Mengistie (2013) employed for the study.

\section{Summary of Findings}

The major findings of the study revealed that:

1. There was significant effect of 12 weeks step aerobics on percentage body fat of obese female nurses in Specialist Hospital Bauchi, Bauchi State $(p<0.001)$.

2. There was no significant effect of 12 weeks step aerobics on visceral fat of obese female nurses in Specialist Hospital Bauchi, Bauchi State $\mathrm{p}<0.0425)$. 


\section{Conclusions}

Based on the findings of the study the following conclusions were drawn:

i. Step aerobics reduced percentage body fat of obese female nurses in Specialist Hospital Bauchi, Bauchi State.

ii. Step aerobics had no significant effect on visceral fat of obese female nurses in Specialist Hospital Bauchi, Bauchi state.

\section{Recommendations}

Based on these findings the researcher recommend as follows:

i. Obese female nurses should be enlightened through public lectures by exercise and sport science specialist on the need to perform regular step aerobics to burn down excess body fat.

ii. Step aerobics should be encouraged among obese female nurses by exercise and sports science specialist as a mode of exercise for improving physical fitness so as to improve their health. 


\section{References}

Arslan, F; (2011).The effect of an eight week step aerobic dance exercise program on body composition parameters in middle aged sedentary obese women. Journal of international Sport Medicine, 12 (4), 160-168.

Cakmackci, E. Arslan, F; Taskin, H \&Cakmackci, O. (2011) Effect of Aerobic Dance Exercise on Body Composition Changes Associated with Weight Changes in Sedentary Women. Journal of Physical Education and Sport Science 13 (3): 296 - 304.

Chumlea, W.C, (2006). Body composition assessment of obesity. Department of Community health and paediatrics life span health centre, Wright State University School of Medicine, U.S A.

Duman, S; (2013). Effect of step aerobic exercise on body composition and depression levels of women in menopause. Middle East Journal of Scientific Research, 16 (2), 172-178.

Ebbert, J.O \& Jensen, M.D, (2013). Fat depots, free fatty acids and dyslipidaemia. Nutrients, 5; 498-508.

Hamid, A; Rastegar, H; \& Ayoub, B, (2012 ). A comparison of body fat and blood pressure between physical education and non-physical education major students. FactaUniversity Physical Education and Sports, 10 (2), 127-134.

Kirchengast, S. (2010). Gender Differences in Body Composition from Childhood to Old Age: An Evolutionary Point of View. Journal of Life Science, 2(1), 1-10.

Kwon, H. R; Min, K.W; Ahn, H. J; Soek, H. G; Koo, B. K; Kim, H. C \& Han, K. A, (2010). Effects of Aerobic Exercise on Abdominal Fat, Thigh Muscle Mass and Muscle Strength in Type2 Diabetic Subject. Korean Diabetes Journal, 34; 23-31.

Lehri, A. \&Mokha, R. (2006). Effectiveness of Aerobic and Strength Training in Causing Weight Loss and Favourable Body Composition in Females. Journal of Science and Physiotherapy, 2; 96- 99.

Mengetie, B.A; (2013). Effect of Concurrent Aerobic and Resistance Exercise Training on Obese Men Adults, North West Ethiopia. Journal of Research in Science and Technology, 2 (4), $1-10$.

Mengisties, A. B; Reddy, R.C; \&Syam, B.M; (2013). The Effects of Combined Aerobic and Resistance Exercise Training on Obese Adults, North West Ethiopia. Research Journal of Recent Sciences, 2(1), 59-66.

Merrick, J; Bacher, A; Carmeli, E; \&Kodesh,E.(2013). Effects of Aerobic Exercise on Body Composition and Muscle Strength in Overweight to Obese Old Women with Intellectual Disability: A pilot study. Open Rehabilitation Journal, 6; 43-48. 
Journal DOI: 10.46654/ij.24889849

Najafnia, Y., Bararpour, E., Amirinejahad, B., \&Nakhaee, H. (2013). Effects of 8-week step aerobic exercise on women's physiological characteristics, body fat percentage, and quality of life. International Journal of Sport Studies, 3(12), 1335-1341.

Sandeep, S; Gokulakrishnan, K; Valmurugan, K; Deepa, M; \& Mohan, V, (2010). Visceral and Subcutaneous Abdominal Fat in Relation to Insulin Resistance and Metabolic Syndrome in Non-Diabetic South Indians. Indian Journal of Medicine, 131; 629-635

Uygur, E; Ucok, K; Genc, A; Sener, U; Uygur, R; \&Songur, A; (2013). Significant Features of Basal and Maximal Energy Expenditure Parameters in Obese Adults. Turkish Journal of Medical Sciences, 43; 863-869

Vatansev, H. \&Cakmakci, E. (2010). The Effect of Eight Week Aerobic Exercise on Blood Lipid and Body Composition of Overweight and Obese Females. Science, Movement and Health, 2; 814-820

Venkatswarlu, K. (2011). Exercise for Disease Prevention and Health Promotion. Nigeria, Ahmadu Bello university press limited Zaria.

Willis, L.H; Slentz, C.A; Bateman, L.A; Shields, A.T; Piner, L.W; Bales, C.W, Houmard, J.A; \& Kraus, W.E; (2012). Effect of Aerobic and/or Resistance Training on Body Mass and Fat Mass in Overweight or Obese Adults. Journal of Applied Physiology, 10; 1152 